\title{
Parental use of the Internet to seek health information and primary care utilisation for their child: a cross-sectional study Gauthier Bouche* and Virginie Migeot
}

\author{
Address: Unité d'évaluation médicale, Pôle Pharmacie et Santé Publique, CHU et Université de Poitiers, Poitiers, France \\ Email: Gauthier Bouche* - gauthier.bouche@univ-poitiers.fr; Virginie Migeot - virginie.migeot@univ-poitiers.fr \\ * Corresponding author
}

Published: 28 August 2008

BMC Public Health 2008, 8:300 doi:10.1 186/147/-2458-8-300

This article is available from: http://www.biomedcentral.com/I47/-2458/8/300

(C) 2008 Bouche and Migeot; licensee BioMed Central Ltd.

This is an Open Access article distributed under the terms of the Creative Commons Attribution License (http://creativecommons.org/licenses/by/2.0), which permits unrestricted use, distribution, and reproduction in any medium, provided the original work is properly cited.
Accepted: 28 August 2008
Received: 17 January 2008

\begin{abstract}
Background: Using the Internet to seek health information is becoming more common. Its consequences on health care utilisation are hardly known in the general population, in particular among children whose parents seek health information on the Internet. Our objective was to investigate the relationship between parental use of the Internet to seek health information and primary care utilisation for their child.
\end{abstract}

Methods: This cross-sectional survey has been carried out in a population of parents of pre-school children in France. The main outcome measure was the self-reported number of primary care consultations for the child, according to parental use of the Internet to seek health information, adjusted for the characteristics of the parents and their child respectively, and parental use of other health information sources.

Results: A total of I 068 out of 2197 questionnaires were returned (response rate of $49 \%$ ). No association was found between parental use of the Internet to seek health information and the number of consultations within the last 12 months for their child. Variables related to the number of primary care consultations were characteristics of the child (age, medical conditions, homeopathic treatment), parental characteristics (occupation, income, stress level) and consultation of other health information sources (advice from pharmacist, relatives).

Conclusion: We did not find any relationship between parental use of the Internet to seek health information and primary care utilisation for children. The Internet seems to be used as a supplement to health services rather than as a replacement.

\section{Background}

Using the Internet to seek health information is becoming more common in Europe [1] as well as in the USA [2]. In France little data is available on the proportion of people who have ever used the Internet to seek health information [3] but this proportion seems to be increasing rapidly (from $15 \%$ in 2002 [1] to $37 \%$ in 2005 [4]).
People use the Internet to seek health information because of its advantages. The Internet is widely available (home, work, libraries), convenient ( $24 \mathrm{~h}$ a day) and anonymous. A recent review highlighted the main reasons of using the Internet to seek health information: to gather additional information after a consultation, to access more complex information about a symptom, a disease or 
a treatment, to look for information about healthy lifestyles or healthcare services, to participate in an online support group and to be aware of other treatment alternatives [5]. Specific surveys have been carried out in samples of parents looking for health information. Many studies asked parents attending a paediatric hospital whether and why they used the Internet to seek heath information. A high proportion of parents attending outpatient departments seek health information online (from 53\% to $64 \%$ in the most recent articles) [6-8]. This proportion is even higher for parents of children with a chronic disease or condition (from 58\% to 89\%) [9-11]. The authors highlighted that health professionals should advise a few selected websites to parents. Population-based surveys pointed out that mothers are high information seekers [12], especially during pregnancy and during the first few years following delivery look to find parenting advice and online clinical health information [12-14].

The widespread utilisation of the Internet raises some questions about its impact on health behaviour, health services utilisation and finally on health outcomes. Although some characteristics of Internet users who seek health information have been well identified [3,15-17], no sufficient data is available to answer the above questions, in particular on the relation between seeking health information on the Internet and health care utilisation.

Some observers have suggested that use of the Internet might actually decrease the cost of primary care services in systems with universal health care [18]. In that case, one might expect a negative relationship between use of the Internet and primary care utilisation. Others might speculate that Internet usage represents just another channel for activated, information-seeking behaviour, in which case the prediction might be for a positive relationship with primary care utilisation. Results from the studies about the impact of the Internet on health care utilisation are heterogeneous, showing a positive relationship between Internet use and service utilisation [19], a negative relationship [20,21] or no relationship at all [22,23]. All these studies but one [21] were carried out within an adult population and none have been conducted elsewhere than in the USA.

Since the health of young children is of particular concern to parents, we assume that parental use of the Internet to seek health information would be related to primary care utilisation for their children. As we previously stated, results from studies available in the literature were heterogeneous [19-23]. Thus, we did not initially presume a positive or negative association.

To test this association, we designed a cross-sectional study in a population of parents of pre-school children. In this paper, we examined the relationship between parental use of the Internet to seek health information and selfreported primary care consultation frequency for their children.

\section{Methods \\ Study design, study population and sample size}

We designed a cross-sectional survey carried out within a population of parents of pre-school children in the department of Vienne, France. In France, even if preschool attendance is not compulsory, almost $100 \%$ of children aged 3 to 6 years attend pre-school ("écoles maternelles"). We defined 7 pre-school strata according to their private or public status and to their rural, semi-urban, urban or ZEP location [ a ZEP school (Zone d'Education Prioritaire) is a school located in an underprivileged area. It benefits from additional resources to cope with academic and social problems. No ZEP private school exists in the Vienne area]. We selected certain schools in each of the 7 strata to ensure the representativeness of our sample according to the characteristics of the schools.

To show a difference of at least one consultation in the last 12 months between those who use the Internet to seek health information (seekers) and those who do not (nonseekers), we needed 750 questionnaires (250 of seekers and 500 of non-seekers), expecting a proportion of one seeker for two non-seekers [4], to meet our objective (twotailed hypothesis, $80 \%$ power, 5\% alpha). Expecting a response rate of $35 \%$, we sent out more than 2100 questionnaires. To meet the required sample size we selected 35 schools which represented a population of 2197 children.

\section{Data collection}

In June 2007, with the help of pre-school principals, the parents of pre-school children were given a letter including an anonymous questionnaire, an explanatory note, and an envelope to return the questionnaire. Parents were asked to answer for their youngest schoolgoing child.

The data collected was: parental characteristics, characteristics of their child, primary care consultation frequency for their child, and health information sources and methods used to seek health information on the Internet. The parental characteristics noted included age, household occupation according to the most advantaged occupation of either of the parents (disadvantaged (workers and unemployed), moderately advantaged (self-employed and employees) or advantaged (managers and executives)), parental education level according to the highest education level accomplished by either of the parents (elementary-secondary, high school diploma, lower tertiary or higher tertiary), annual family income (<14 000 , from 14000 to 19999 , from 20000 to 29999 , from 
30000 to 39999 and $\geq 40000$ ), single parent family, place of residence (urban, rural), stress level assessed with a 10-unit visual analogue rating scale (10 indicative of higher stress) and Internet access (home, work only, none). The characteristics of the child collected were school attended, age, birth order, gender, medical conditions if any (preterm infant, hospitalisation after birth, asthma, wearing of glasses, auditory disorders, allergy, behavioural disorder, surgical intervention and others), long-term use of medication if any, whether under homeopathic treatment, frequency of administration of over the counter drugs to their child without medical advice and whether the parents had taken advice from a pharmacist for their child within the last 12 months. We asked parents to self-report the number of primary care consultations for their child within the last 12 months (general practitioner, paediatrician or accidents and emergency department). For consultations and child's medical conditions, we asked parents to refer to their child's health record booklet if necessary. Parents were also asked about other health information sources that they had already used amongst the Internet, medical books, medical dictionaries, television, press, relatives working in the medical sector, and other relatives.

The study as a whole had been previously approved by the consultative committee on the processing of information in medical research of CNIL, the French national commission on individual privacy (approval AR071193).

\section{Statistical analysis}

The dependant variable was the number of primary care consultations. The explanatory variables were child's age, child's birth order, child's medical condition and treatment, parental age, socio-economic position of the family, single parent family, parental stress level and health information sources. The main variable of interest was parental use of the Internet to seek health information.

We assumed that the number of primary care consultations followed a negative binomial distribution - an extension of the Poisson distribution in case of over-dispersion $[24,25]$. We therefore used a negative binomial regression model to explain the variability of the number of consultations. We took the design effect (cluster effect) into account to avoid errors in the estimation of the parameters of the model [26].

To perform our analysis, we used the negbin function of STATA [27] along with the svy option to take the design effect into account. The variable "parental use of the Internet to seek health information" was forced into the model. Other variables were included in the initial regression model if they were associated with the number of consultations with a p-value $<0.20$ (using bivariate nega- tive binomial regression). We then performed a multivariate analysis. From the initial regression model, variables were selected using a stepwise descending process. We tested the first-order interactions in the final model. Association between the number of consultations and variables of interest are rate ratios.

\section{Results \\ Response rate and characteristics of the study population} Of the 2197 questionnaires distributed, 1068 questionnaires were returned (49\%). Characteristics of the population are presented in Table 1 . The mean number of primary care consultations for a pre-school child within the last 12 months was $5.9 \pm 4.6$. Distribution of the selfreported number of primary care consultations is shown in Figure 1, which confirms the assumption of a negative binomial distribution. Data on the number of consultations were missing for 39 questionnaires (4\%).

The Internet was the most used health information source with 556 families (52\%) who at least once had used it to seek health information. Relatives working in the medical sector and television were the second and third most common health information sources, with 518 (49\%) and 397 (37\%) families respectively having at least once used these sources (Figure 2).

\section{Use of the Internet to seek health information and number of primary care consultations for their child}

Mean numbers of consultations according to population characteristics together with results of the bivariate analysis are presented in Table 2 . The multivariate analysis has been carried out on the 886 questionnaires (83\%) for which no data was missing. Four variables were dropped due to the stepwise regression analysis (parental age, single parent family, allergy and television as health information source). None of the first-order interactions between explanatory variables of the final model were significant. Results of the multivariate analysis are presented in Table 3. No association was found between use of the Internet to seek health information and the number of consultations within the last 12 months (adjusted rate ratio 0.97; $95 \%$ CI 0.86 to 1.09 ). Seeking health information from relatives (whether they were from the medical sector or not) was associated with a slight increase in the number of consultations. The main variables related to the number of primary care consultations were child's age and medical condition. Number of consultations within the last 12 months decreased with child's age (with a decrease of $16 \%, 23 \%$ and $33 \%$ for children aged 4,5 and 6 years respectively compared to children aged 2 or 3 years). Most of the children's medical conditions were positively related to the number of consultations. Some parental characteristics were related to a lower number of consultations: moderately advantaged occupation and annual 
Table I: Characteristics of the 1068 pre-school children and their parents

\begin{tabular}{|c|c|c|c|}
\hline \multicolumn{4}{|l|}{ Characteristics } \\
\hline Characteristics of the children & & $\mathrm{N}$ & $\%$ \\
\hline \multirow[t]{4}{*}{ Age $(n=1067)$} & - 2 or 3 years old & 227 & $21 \%$ \\
\hline & - 4 years old & 335 & $31 \%$ \\
\hline & - 5 years old & 328 & $31 \%$ \\
\hline & -6 years old & 177 & $17 \%$ \\
\hline Girls $(n=1068)$ & & 537 & $50 \%$ \\
\hline First in birth order $(n=1039)$ & & 498 & $48 \%$ \\
\hline \multirow[t]{9}{*}{ Medical conditions $(n=1068)$} & - Preterm infant & 96 & $9 \%$ \\
\hline & - Hospitalisation after birth & 81 & $8 \%$ \\
\hline & - Asthma & 156 & $15 \%$ \\
\hline & - Wearing of glasses & 146 & $14 \%$ \\
\hline & - Auditory disorders & 63 & $6 \%$ \\
\hline & - Allergy & 214 & $20 \%$ \\
\hline & - Behavioural disorder & 44 & $4 \%$ \\
\hline & - At least one surgical intervention & 225 & $21 \%$ \\
\hline & - Other medical conditions & 70 & $7 \%$ \\
\hline Long term medication use $(n=1068)$ & & 73 & $7 \%$ \\
\hline \multirow{4}{*}{$\begin{array}{l}\text { Frequency of administrating over the counter drugs without medical advice } \\
(n=1062)\end{array}$} & - Never & 168 & $16 \%$ \\
\hline & - Rarely & 311 & $29 \%$ \\
\hline & - Often & 509 & $48 \%$ \\
\hline & - Almost every time my child is ill & 74 & $7 \%$ \\
\hline Under homeopathic treatment $(n=1043)$ & & 549 & $53 \%$ \\
\hline \multirow[t]{2}{*}{ Advice from a pharmacist within the last 12 months $(n=1051)$} & & 445 & $42 \%$ \\
\hline & & Mean & SD \\
\hline N. of primary care consultations within the last 12 months $(n=1029)$ & & 5.9 & 4.6 \\
\hline Parental characteristics & & $\mathrm{N}$ & $\%$ \\
\hline Single parent family $(n=1066)$ & & 136 & $13 \%$ \\
\hline Rural place of residence $(n=1064)$ & & 217 & $20 \%$ \\
\hline \multirow[t]{3}{*}{ Occupation $(n=1056)$} & - Disadvantaged (workers, unemployed) & 151 & $14 \%$ \\
\hline & - Moderately advantaged (self-employed, employees) & 563 & $53 \%$ \\
\hline & - Advantaged (managers and executives) & 342 & $33 \%$ \\
\hline \multirow[t]{4}{*}{ Education level $(n=1037)$} & - Elementary and secondary & 285 & $27 \%$ \\
\hline & - High school diploma ("Baccalauréat") & 238 & $23 \%$ \\
\hline & - Lower tertiary & 235 & $23 \%$ \\
\hline & - Higher tertiary & 279 & $27 \%$ \\
\hline \multirow[t]{6}{*}{ Annual family income $(n=949)$} & $-<14000 €$ & 168 & $18 \%$ \\
\hline & -14000 to $19999 €$ & 203 & $21 \%$ \\
\hline & -20000 to $29999 €$ & 286 & $30 \%$ \\
\hline & -30000 to $39999 €$ & 170 & $18 \%$ \\
\hline & $-\geq 40000 €$ & 122 & $13 \%$ \\
\hline & & Mean & SD \\
\hline Age of the respondent in year $(n=1058)$ & & 34.0 & 5.0 \\
\hline Parental stress level $(n=1040)$ & & 4.9 & 2.3 \\
\hline
\end{tabular}

income from 20000 and over. Parental stress was related to a higher number of consultations with a $3 \%$ increase in the number of consultations for every one-unit increase in the visual analogue rating scale.

We also fitted a model without income on the 974 families $(91 \%)$ for whom no data other than income was missing (data not shown). Results were very similar though associations of auditory disorders and homeopathic treatment with the number of consultations were not significant anymore.

\section{Discussion}

We did not find any relationship between parental use of the Internet to seek health information and the number of self-reported consultations for their child. This finding 


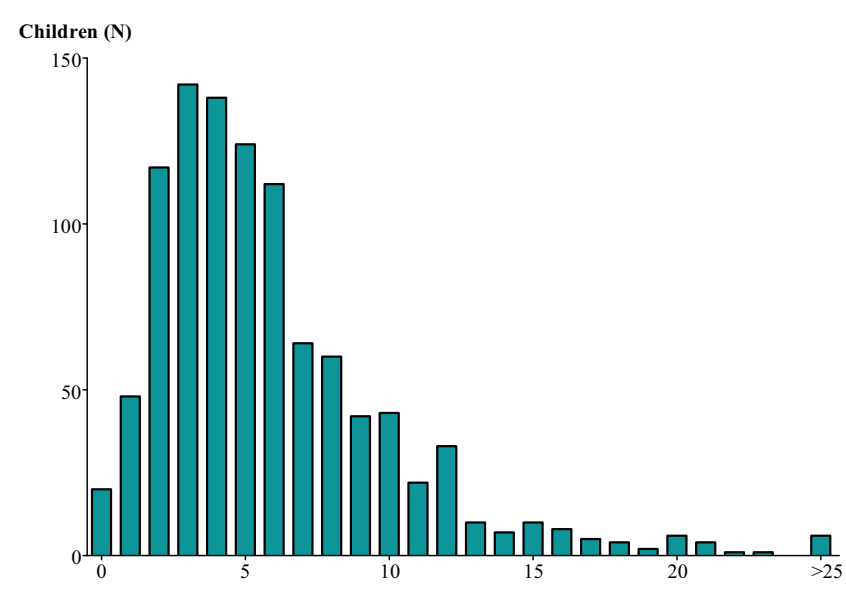

Figure I

Distribution of the self-reported number of primary care consultations for the child within the last 12 months.

runs counter to our initial assumption that parental use of the Internet to seek health information would be related to primary care utilisation, either in a positive or in a negative way.

To our knowledge, this is the first study carried out elsewhere than in the USA to assess this relationship. Our results are consistent with an interventional study on mental health services utilisation, which did not find any significant difference in the number of mental health visits between a group that had Web site access and the control group [22]. A quasi-experimental study carried out by Wagner et al. found a null association for parents [23] and a negative association for children [21]. Data from this study are not fully comparable with our study because the

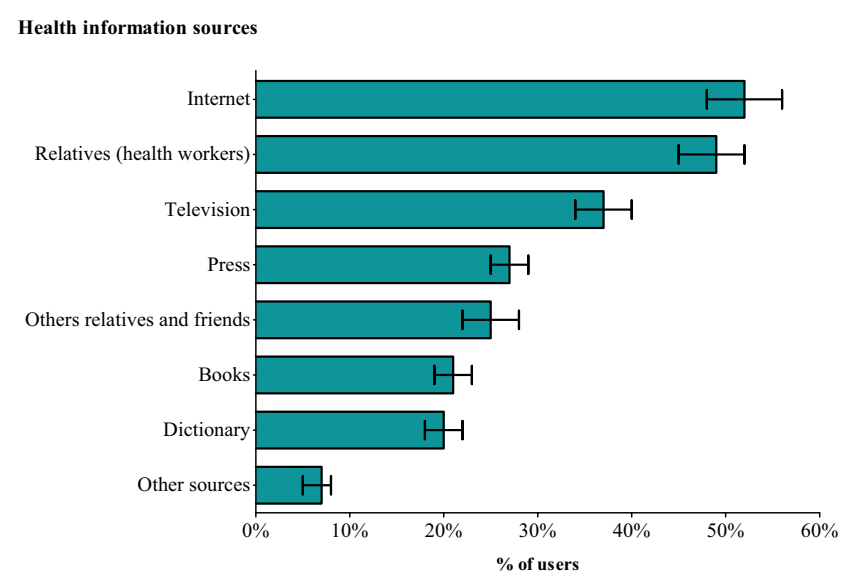

\section{Figure 2}

Frequency (and 95\% confidence intervals) of the different health information sources used by the I 068 parents. intervention was complex and not entirely Internet-based (self-care books, telephone advice nurses and computers). Within a population of Internet users, Eastin and Guinsler found an interaction between anxiety and Internet use to seek health information [20]. Anxious individuals who used the Internet to seek health information had fewer consultations than anxious non-users, whereas such a difference was not found for less anxious individuals. Our findings do not corroborate this interaction, since we did not find any interaction between stress levels and parental use of the Internet to seek health information. Another American study conducted in 1999-2000 found a positive association with an increase of 1.6 consultations for women using computer-based resources [19]. Differences in time period (1999-2000), geographical area (Baltimore metropolitan area, USA) and potential selection bias in both studies are likely to explain the differences between these results and our findings. Finally, findings from a cross-sectional study in seven European countries that investigated patterns of health-related Internet use and its consequences support our results. Only $6 \%$ of the sample claimed that they had made, cancelled or changed a doctor's appointment based on health related Internet activity [28]. Even if the number of consultations was not collected in this study, only $6 \%$ of the sample claimed that they have made, cancelled or changed a doctor's appointment based on health related Internet activity.

The association that we found between primary care utilisation and the child's age [29-31], child's medical condition [29], familial socio-economic position [32] and psychological factors [33] are consistent with previous findings. However, in most studies performed in the USA $[29,30,34]$, lower socio-economic position was associated with less frequent primary care utilisation, which is contrary to our results. Explanations are likely to come from the differences between the French and the American health insurance coverage for children. In France, health insurance coverage is nearly universal [35]. In the USA, most of the studies have been carried out in the 1990's or before, when the problem of uninsured children was raised $[29,30,34]$. At that time, children from the poorest families were more likely to be uninsured resulting in a lower number of primary care consultations. A few new factors associated with the number of primary care consultations have been identified in our study. Taking advice from a pharmacist, using relatives or friends as a health information source or using homeopathy for one's child could be explained by increased parental consciousness of health issues. These findings might reflect the "familial context" mentioned by Cardol [36] which would explain about $20 \%$ of the variability of the number of consultations in primary care. 
Table 2: Relation between mean number of primary care consultations for the child and population characteristics - bivariate negative regression analysis.

\begin{tabular}{|c|c|c|c|c|c|}
\hline \multicolumn{3}{|l|}{ Explanatory variables ( $\mathrm{n}=1029$ unless otherwise indicated) } & \multirow[t]{2}{*}{ Mean } & \multirow[t]{2}{*}{ SD } & \multirow[t]{2}{*}{$P$} \\
\hline Health information sources & & & & & \\
\hline \multirow[t]{2}{*}{ Medical dictionary } & No & $n=826$ & 5.8 & 4.2 & 0.38 \\
\hline & Yes & $n=203$ & 6.3 & 5.8 & \\
\hline \multirow[t]{2}{*}{ Internet } & No & $n=490$ & 5.9 & 4.7 & 0.92 \\
\hline & Yes & $n=539$ & 5.9 & 4.5 & \\
\hline \multirow[t]{2}{*}{ Press } & No & $n=753$ & 5.8 & 4.3 & 0.20 \\
\hline & Yes & $n=276$ & 6.3 & 5.2 & \\
\hline \multirow[t]{2}{*}{ Medical books } & No & $\mathrm{n}=809$ & 5.8 & 4.5 & 0.21 \\
\hline & Yes & $\mathrm{n}=220$ & 6.3 & 4.9 & \\
\hline \multirow[t]{2}{*}{ Television } & No & $n=646$ & 5.7 & 4.2 & 0.05 \\
\hline & Yes & $\mathrm{n}=383$ & 6.2 & 5.1 & \\
\hline \multirow[t]{2}{*}{ Relatives working in the medical sector } & No & $n=528$ & 5.6 & 4.2 & 0.004 \\
\hline & Yes & $\mathrm{n}=50 \mathrm{I}$ & 6.3 & 5.0 & \\
\hline \multirow[t]{2}{*}{ Other relatives } & No & $\mathrm{n}=779$ & 5.7 & 4.4 & 0.006 \\
\hline & Yes & $n=250$ & 6.6 & 5.0 & \\
\hline \multicolumn{6}{|l|}{ Characteristics of the child } \\
\hline \multirow[t]{4}{*}{ Age $(n=1028)$} & $2-3$ years old & $n=221$ & 7.3 & 5.6 & 0.0001 \\
\hline & 4 years & $n=319$ & 6.0 & 3.8 & \\
\hline & 5 years & $n=317$ & 5.6 & 5.0 & \\
\hline & 6 years & $n=|7|$ & 4.7 & 3.1 & \\
\hline \multirow[t]{2}{*}{ First in birth order $(n=1002)$} & No & $n=523$ & 5.8 & 4.8 & 0.41 \\
\hline & Yes & $n=479$ & 6.1 & 4.4 & \\
\hline \multirow[t]{2}{*}{ Child gender } & Boy & $n=514$ & 6.0 & 4.9 & 0.71 \\
\hline & Girl & $n=515$ & 5.9 & 4.2 & \\
\hline \multicolumn{6}{|l|}{ Medical conditions } \\
\hline \multirow[t]{2}{*}{ Preterm infant $(n=1025)$} & No & $\mathrm{n}=933$ & 5.9 & 4.5 & 0.21 \\
\hline & Yes & $\mathrm{n}=92$ & 6.6 & 5.4 & \\
\hline \multirow[t]{2}{*}{ Hospitalisation after birth $(n=1023)$} & No & $n=948$ & 5.9 & 4.5 & 0.34 \\
\hline & Yes & $\mathrm{n}=75$ & 6.6 & 5.7 & \\
\hline \multirow[t]{2}{*}{ Asthma } & No & $\mathrm{n}=879$ & 5.6 & 4.4 & $<0.0001$ \\
\hline & Yes & $\mathrm{n}=150$ & 7.9 & 5.1 & \\
\hline Wearing of glasses & No & $n=888$ & 5.8 & 4.3 & 0.05 \\
\hline & Yes & $n=|4|$ & 6.7 & 6.2 & \\
\hline Auditory disorders & No & $\mathrm{n}=967$ & 5.8 & 4.6 & 0.006 \\
\hline & Yes & $n=62$ & 7.4 & 4.6 & \\
\hline Allergy & No & $\mathrm{n}=825$ & 5.6 & 4.6 & $<0.0001$ \\
\hline & Yes & $n=404$ & 7.3 & 4.4 & \\
\hline Behavioural disorder & No & $\mathrm{n}=987$ & 5.9 & 4.6 & 0.88 \\
\hline & Yes & $\mathrm{n}=42$ & 5.8 & 4.2 & \\
\hline At least one surgical intervention & No & $\mathrm{n}=817$ & 5.7 & 4.6 & 0.0004 \\
\hline & Yes & $n=212$ & 6.8 & 4.4 & \\
\hline Other medical conditions & No & $n=960$ & 5.9 & 4.5 & 0.10 \\
\hline & Yes & $n=69$ & 6.7 & 5.0 & \\
\hline Long term medication use & No & $n=961$ & 5.7 & 4.5 & $<0.0001$ \\
\hline & Yes & $n=68$ & 8.9 & 5.2 & \\
\hline Frequency of administrating over the counter drugs without medical & Never & $\mathrm{n}=158$ & 5.8 & 5.0 & 0.63 \\
\hline & Rarely & $\mathrm{n}=300$ & 5.8 & 4.3 & \\
\hline & Often & $n=494$ & 6.1 & 4.7 & \\
\hline & Almost every time my child is ill & $n=73$ & 5.5 & 4.4 & \\
\hline Under homeopathic treatment $(\mathrm{n}=1008)$ & No & $n=474$ & 5.6 & 4.3 & 0.08 \\
\hline & Yes & $\mathrm{n}=534$ & 6.2 & 4.8 & \\
\hline Advice from a pharmacist within the last 12 months $(n=1027)$ & No & $n=592$ & 5.4 & 4.2 & 0.0003 \\
\hline & Yes & $n=435$ & 6.6 & 5.0 & \\
\hline
\end{tabular}


Table 2: Relation between mean number of primary care consultations for the child and population characteristics - bivariate negative regression analysis. (Continued)

\begin{tabular}{|c|c|c|c|c|c|}
\hline Parental characteristics & & & & & \\
\hline \multirow[t]{2}{*}{ Single parent family $(n=1028)$} & No & $n=899$ & 5.8 & 4.3 & 0.02 \\
\hline & Yes & $n=129$ & 6.7 & 6.0 & \\
\hline \multirow[t]{3}{*}{ Occupation $(n=1019)$} & Disadvantaged & $n=142$ & 6.8 & 6.3 & 0.04 \\
\hline & Moderately advantaged & $\mathrm{n}=542$ & 5.9 & 4.6 & \\
\hline & Advantaged & $\mathrm{n}=335$ & 5.6 & 3.6 & \\
\hline \multirow[t]{4}{*}{ Education level $(n=1002)$} & Elementary and secondary & $n=268$ & 6.6 & 6.2 & 0.20 \\
\hline & High school diploma & $n=233$ & 5.9 & 4.1 & \\
\hline & Lower tertiary & $n=232$ & 5.6 & 3.6 & \\
\hline & Higher tertiary & $n=269$ & 5.7 & 3.9 & \\
\hline \multirow{5}{*}{ Annual family income $(n=92 I)$} & $<14000 €$ & $n=159$ & 7.2 & 7.4 & 0.03 \\
\hline & 14000 to $19999 €$ & $\mathrm{n}=195$ & 5.8 & 3.9 & \\
\hline & 20000 to $29999 €$ & $n=279$ & 5.5 & 3.5 & \\
\hline & 30000 to $39999 €$ & $n=167$ & 5.9 & 3.9 & \\
\hline & $\geq 40000 €$ & $n=12 \mid$ & 5.4 & 3.9 & \\
\hline \multirow[t]{3}{*}{ Rural place of residence $(n=1025)$} & No & $\mathrm{n}=815$ & 5.9 & 4.7 & 0.88 \\
\hline & Yes & $n=210$ & 5.9 & 4.3 & \\
\hline & & & Rate Ratio & & $95 \% \mathrm{Cl}$ \\
\hline Age of the respondent $(n=1020)$ & & & 0.98 & & {$[0.97-0.99]$} \\
\hline Parental stress level $(n=1005)$ & & & 1.03 & & {$[1.01-1.06]$} \\
\hline
\end{tabular}

The first limitation of our study was the overall response rate of $49 \%$. However, details of response rates of each school gave us information to identify the bias due to non-responses. We found that response rates were lower in schools with a higher proportion of families of low socio-economic position and with a higher proportion of non-French speaking families. We therefore probably over-estimated the proportion of families who used the Internet to seek health information, and possibly underestimated the mean number of consultations. The second limitation was that data on race/ethnicity was not asked in the questionnaire. According to the French population statistics, less than five percent of the inhabitants of the department of Vienne are non native French. In this context, race/ethnicity is not so important even if it is well established in the American context that disparities in Internet use for health information exist according to race/ethnicity

$[37,38]$.

Another limitation was that the number of consultations was self-reported by the parents. Many studies have shown a tendency for underestimation when people were asked to report the frequency of their health care utilisation. Since we found a mean of 5.9 consultations per child within the last 12 months, which is consistent with the data of health care utilisation from the provider [39], the bias may be small. Missing data for parental income was another limitation, with 119 (11\%) parents who did not report their annual family income. This omission in reporting annual family incomes is information probably not missing at random because it is more likely to occur when the income level is relatively high [40].

\section{Conclusion}

Even if our study had some limitations, we demonstrated that there was no relationship between parental use of the Internet to seek health information and primary care consultation of their children. The Internet seems to be used as a supplement to health services for some rather than as a replacement. Individuals are increasingly involved in the management of their own health and using the Internet to seek health information is one way to be involved actively. Some authors suggested that this would lead to saving in health costs [18]. According to our findings, this may not be true from a short-term perspective. In our opinion, what is more likely to occur is an improvement in the health of those who use the Internet to seek health information, which, from a long-term perspective, would eventually lead to saving in health costs.

\section{Competing interests}

The authors declare that they have no competing interests.

\section{Authors' contributions}

GB designed the study, collected the data and had primary responsibility for data analysis and manuscript preparation. VM helped with the implementation of the study, validated the methodology and contributed to data analysis and manuscript preparation. All authors read and approved the final manuscript.

\section{Acknowledgements}

The authors would like to thank the school principals and parents who participated in the study, Dr Chantal Simmat who helped us for the study implementation in schools and $\operatorname{Pr}$ Pierre Ingrand for his support. We also wish to thank Dr Shivani Aguilera for the English revision. 
Table 3: Relation between number of primary care consultations for the child and population characteristics - multivariate analysis.

\begin{tabular}{|c|c|c|c|}
\hline Explanatory variables & & Adjusted Rate Ratio* & $95 \% \mathrm{Cl}$ \\
\hline \multicolumn{4}{|l|}{ Health information sources } \\
\hline \multirow[t]{2}{*}{ Internet } & No & I & \\
\hline & Yes & 0.97 & {$[0.86-1.09]$} \\
\hline \multirow[t]{2}{*}{ Relatives working in the medical sector } & No & I & \\
\hline & Yes & 1.08 & {$[1.01-1.16]$} \\
\hline \multirow[t]{2}{*}{ Other relatives } & No & I & \\
\hline & Yes & 1.12 & {$[1.01-1.25]$} \\
\hline \multicolumn{4}{|l|}{ Characteristics of the child } \\
\hline \multirow[t]{4}{*}{ Age } & $2-3$ years old & 1 & \\
\hline & 4 years & 0.84 & {$[0.73-0.96]$} \\
\hline & 5 years & 0.77 & {$[0.65-0.90]$} \\
\hline & 6 years & 0.67 & {$[0.56-0.80]$} \\
\hline \multicolumn{4}{|l|}{ Medical conditions } \\
\hline \multirow[t]{2}{*}{ Asthma } & No & I & \\
\hline & Yes & 1.28 & {$[1.13-1.46]$} \\
\hline \multirow[t]{2}{*}{ Wearing of glasses } & No & I & \\
\hline & Yes & 1.19 & {$[1.03-1.45]$} \\
\hline \multirow[t]{2}{*}{ Auditory disorders } & No & I & \\
\hline & Yes & 1.23 & {$[1.03-1.46]$} \\
\hline \multirow{2}{*}{ At least one surgical intervention } & No & I & \\
\hline & Yes & 1.12 & {$[1.02-1.22]$} \\
\hline \multirow[t]{2}{*}{ Long term medication use } & No & I & \\
\hline & Yes & 1.26 & {$[1.06-1.49]$} \\
\hline \multirow[t]{2}{*}{ Under homeopathic treatment } & No & 1 & \\
\hline & Yes & 1.13 & {$[1.03-1.23]$} \\
\hline \multirow[t]{2}{*}{ Advice from a pharmacist within the last 12 months } & No & 1 & \\
\hline & Yes & 1.14 & {$[1.05-1.24]$} \\
\hline \multicolumn{4}{|l|}{ Parental characteristics } \\
\hline \multirow[t]{3}{*}{ Occupation } & Disadvantaged & 1 & \\
\hline & Moderately advantaged & 0.85 & {$[0.75-0.96]$} \\
\hline & Advantaged & 0.87 & {$[0.75-1.02]$} \\
\hline \multirow[t]{5}{*}{ Annual family income } & $<14000 €$ & 1 & \\
\hline & 14000 to $19999 €$ & 0.86 & {$[0.73-1.01]$} \\
\hline & 20000 to $29999 €$ & 0.80 & {$[0.68-0.94]$} \\
\hline & 30000 to $39999 €$ & 0.87 & {$[0.76-0.99]$} \\
\hline & $\geq 40000 €$ & 0.80 & {$[0.64-0.99]$} \\
\hline Parental stress level & & 1.03 & {$[1.01-1.05]$} \\
\hline
\end{tabular}

* Adjusted on other health information sources (dictionary, press, books and television), characteristics of the child (birth order, gender, medical conditions - preterm infant, hospitalisation after birth, allergy, behavioral disorder - frequency of administrating over the counter drugs without medical advice) and parental characteristics (age, single parent, education level and place of residence).

\section{References}

I. Spadaro R: Eurobarometer 58.0. European Union, citizens and sources of information about health. The European Opinion Research Group (EORG) 2003:16.

2. Fox S: Online Health Search 2006. Washington, DC: Pew Internet \& American Life Project; 2006.

3. Renahy E, Chauvin P: Internet uses for health information seeking: A literature review. Rev Epidemiol Sante Publique 2006, 54:263-75.

4. Renahy E, Parizot I, Chauvin P: Internet uses for health information seeking: a new digital divide? A study on a representative sample of Paris metropolitan area, France, 2005 [abstract]. II th World Congress on Internet in Medicine (MedNet), October 13-20, 2006, Toronto . abstract book: 100
5. McMullan M: Patients using the Internet to obtain health information: How this affects the patient-health professional relationship. Patient Educ Couns 2006, 63:24-28.

6. Sim NZ, Kitteringham L, Spitz L, Pierro A, Kiely E, Drake D, Curry J: Information on the World Wide Web - how useful is it for parents? J Pediatr Surg 2007, 42:305-12.

7. Wainstein BK, Sterling-Levis K, Baker SA, Taitz J, Brydon M: Use of the Internet by parents of paediatric patients. J Paediatr Child Health 2006, 42:528-32.

8. Semere $W$, Karamanoukian HL, Levitt M, Edwards T, Murero M, D'Ancona G, Donias HW, Glick PL: A pediatric surgery study: parent usage of the Internet for medical information. J Pediatr Surg 2003, 38:560-4. 
9. Shah A, Kuo A, Zurakowski D, Waters PM: Use and satisfaction of the internet in obtaining information on brachial plexus birth palsies and its influence on decision-making. J Pediatr Orthop 2006, 26:78|-4.

10. Lu C, Wirrell E, Blackman M: Where do families of children with epilepsy obtain their information? J Child Neurol 2005, 20:905-10.

II. Ikemba CM, Kozinetz CA, Feltes TF, Fraser CD Jr, McKenzie ED, Shah N, Mott AR: Internet use in families with children requiring cardiac surgery for congenital heart disease. Pediatrics 2002, 109:419-22.

12. Allen K: Parents online. Washington, DC: Pew Internet \& American Life Project; 2000.

13. Sarkadi A, Bremberg S: Socially unbiased parenting support on the Internet: a cross-sectional study of users of a large Swedish parenting website. Child Care Health Dev 2005, 31:43-52.

14. Bernhardt JM, Felter EM: Online pediatric information seeking among mothers of young children: results from a qualitative study using focus groups. J Med Internet Res 2004, 6:e7.

15. Cotten SR, Gupta SS: Characteristics of online and offline health information seekers and factors that discriminate between them. Soc Sci Med 2004, 59:1795-806.

16. Baker L, Wagner TH, Singer S, Bundorf MK: Use of the Internet and e-mail for health care information: results from a national survey. JAMA 2003, 289:2400-6.

17. Ybarra ML, Suman M: Help seeking behavior and the Internet: A national survey. Int J Med Inform 2006, 75(I):29-4I.

18. Cayton $\mathrm{H}$ : The flat-pack patient? Creating health together. Patient Educ Couns 2006, 62:288-90.

19. Nicholson W, Gardner B, Grason HA, Powe NR: The association between women's health information use and health care visits. Womens Health Issues 2005, 15:240-8.

20. Eastin MS, Guinsler NM: Worried and wired: effects of health anxiety on information-seeking and health care utilization behaviors. Cyberpsychol Behav 2006, 9:494-8.

21. Wagner TH, Greenlick MR: When parents are given greater access to health information, does it affect pediatric utilization? Med Care 200I, 39:848-55.

22. Azocar F, McCabe JF, Wetzel JC, Schumacher SJ: Use of a behavioral health Web site and service utilization. Psychiatr Serv 2003 54:18.

23. Wagner TH, Hibbard JH, Greenlick MR, Kunkel L: Does providing consumer health information affect self-reported medical utilization? Evidence from the Healthwise Communities Project. Med Care 200I, 39:836-47.

24. Gardner W, Mulvey EP, Shaw EC: Regression analysis of counts and rates: Poisson, overdispersed Poisson, and negative binomial models. Psychol Bull 1995, I I 8:392-404.

25. Byers A, Allore HG, Peduzzi PN, Gill TM: Application of negative binomial modeling for discrete outcomes: $A$ case study in aging research. I Clin Epidemiol 2003, 56:559-564.

26. Killip S, Mahfoud Z, Pearce K: What is an intracluster correlation coefficient? Crucial concepts for primary care researchers. Ann Fam Med 2004, 2:204-8.

27. STATA: Version 9.0 College Station: StataCorp LP; 2005.

28. Andreassen HK, Bujnowska-Fedak MM, Chronaki CE, Dumitru RC, Pudule I, Santana S, Voss H, Wynn R: European citizens' use of Ehealth services: a study of seven countries. BMC Public Health 2007, 7:53.

29. Newacheck PW: Characteristics of children with high and low usage of physician services. Med Care 1992, 30:30-42.

30. Butler JA, Winter WD, Singer JD, Wenger M: Medical care use and expenditure among children and youth in the United States: analysis of a national probability sample. Pediatrics 1985 76:495-507.

31. Weinick RM, Krauss NA: Racial/ethnic differences in children's access to care. Am J Public Health 2000, 90:177I-4

32. Saxena S, Majeed A, Jones M: Socioeconomic differences in childhood consultation rates in general practice in England and Wales: prospective cohort study. BM] 1999, 3 I 8:642-6.

33. Riley AW, Finney JW, Mellits ED, Starfield B, Kidwell S, Quaskey S, Cataldo MF, Filipp L, Shematek JP: Determinants of children's health care use: an investigation of psychosocial factors. Med Care 1993, 31:767-83.
34. Newacheck PW, Hughes DC, Stoddard J]: Children's access to primary care: differences by race, income, and insurance status. Pediatrics 1996, 97:26-32.

35. Rodwin VG: The health care system under French national health insurance: lessons for health reform in the United States. Am J Public Health 2003, 93:3I-7.

36. Cardol M, Groenewegen PP, de Bakker DH, Spreeuwenberg P, van Dijk L, Bosch $W$ van den: Shared help seeking behaviour within families: a retrospective cohort study. BM] 2005, 330:882.

37. Murray E, Lo B, Pollack L, Donelan K, Catania J, White M, Zapert K, Turner $R$ : The impact of health information on the internet on the physician-patient relationship: patient perceptions. Arch Intern Med 2003, 163: 1727-34.

38. Fogel J: Internet use for cancer information among racial/ethnic populations and low literacy groups. Cancer Control 2003, 10:45-51.

39. Caisse Nationale de l'Assurance Maladie des Travailleurs Salariés Direction des Statistiques et des Etudes: La consommation de soins des enfants de moins de 3 ans. Point de conjoncture 2002, 7:18-26.

40. Donders AR, Heijden GJ van der, Stijnen T, Moons KG: Review: a gentle introduction to imputation of missing values. J Clin Epidemiol 2006, 59: |087-9|.

\section{Pre-publication history}

The pre-publication history for this paper can be accessed here:

http://www.biomedcentral.com/1471-2458/8/300/pre pub

Publish with Biomed Central and every scientist can read your work free of charge

"BioMed Central will be the most significant development for disseminating the results of biomedical research in our lifetime. "

Sir Paul Nurse, Cancer Research UK

Your research papers will be:

- available free of charge to the entire biomedical community

- peer reviewed and published immediately upon acceptance

- cited in PubMed and archived on PubMed Central

- yours - you keep the copyright 